\title{
AFETOS POSITIVOS E NEGATIVOS E TRABALHO DOCENTE: PERSPECTIVA DE PROFESSORES DO ENSINO FUNDAMENTAL
}

\author{
Eliane Nascimento Silva, Bárbara Cristina Soares Sena, Camélia Santina Murgo \\ Universidade do Oeste Paulista - UNOESTE, Programa de Pós-Graduação em Educação, Presidente Prudente, SP. E-mail: \\ likans@hotmail.com.
}

\section{RESUMO}

O presente estudo teve como objetivo analisar a forma como professores percebem seus afetos positivos negativos bem como as possíveis interferências dos afetos no trabalho desenvolvido por estes profissionais. investigação foram realizadas entrevistas semiestruturadas com dez professores do 50 ao 9 o ano do Fundamental de uma escola da rede estadual de uma cidade do interior do Estado de São Paulo. O estudo ana afetos positivos e negativos dos professores em categorias especificas, onde notou-se a presença de afetos ne relacionados ao sentimento vivenciado com as exigências presentes no ambiente de trabalho e nas ati exercidas, ficando prevalente expressões de desanimo, cansaço e nervosismo. Já os afetos positivos encontrados em expressões que remetiam a realização bem-sucedida das atividades e dos resultados docentes obtinham das suas ações, sendo a felicidade o afeto mais citado nesta categoria.

Palavras-Chave: Docência; Psicologia Positiva; Afeto Positivo; Afeto Negativo

\section{POSITIVE AND NEGATIVE AFFECTS AND TEACHING WORK: PERSPECTIONS OF TEACHERS FROM ELEMENTARY SCHOOL}

\begin{abstract}
This study aimed to analyze how teachers perceive their positive and negative affect and the possible interference of these affects in their performance as teachers. For this research were conducted semi-structured interviews with ten teachers from 5th to 9th grade of primary education in a state school in a city in the state of São Paulo. The study investigated the positive and negative affects of teachers in specific categories, where it was noticed the presence of negative emotions related to the feelings that are experienced related to the requirements of labor environment, becoming prevalent expressions of discouragement, fatigue and nervousness. Positive affects were found in expressions which referred to the successful realization of the activities and results that teachers obtained thru their actions,bring happiness and affection the most cited in this category.
\end{abstract}

Keywords: Teaching. Positive Psychology. Positive Affect. Negative Affect

\section{INTRODUÇÃO}

$\mathrm{Na}$ última década o construto bem-estar subjetivo tem sido estudado, a partir da vertente da Psicologia Positiva, área está do conhecimento psicológico que tem como foco principal ampliar e 
modificar a direção dos estudos sobre o comportamento humano. Para os pesquisadores desta linha da Psicologia não se deve conceber o homem a partir do que está errado ou ruim, mas (re) construir qualidades positivas. (SELIGMAN, 2004). No decorrer da sua história, o sentido atribuído ao bemestar subjetivo sofreu alterações, chegando-se, atualmente, ao consenso de que o bem-estar é composto por uma dimensão cognitiva (satisfação com a vida), e uma dimensão emocional (afetos positivos e afetos negativos) (GIACOMONI, 2004).

Um contexto no qual se faz urgente à investigação do bem-estar subjetivo é o âmbito laboral. Apesar de não ter um conceito especifico que trate dessa questão a literatura aponta para estudos que se relacionam com o assunto. Sabe-se que o bem-estar subjetivo no trabalho é entendido como um construto psicológico multidimensional que engloba vínculos positivos com o trabalho e com a organização. Os vínculos positivos com o trabalho referem-se à satisfação e envolvimento as atividades ocupacionais, ou seja, seria um estado de prazer resultante de experiência da ocupação, relacionamento com chefia e colegas, contentamento com o salario pago pela empresa, oportunidades de carreira e o comprometimento organizacional afetivo, que seria a identificação com uma organização especifica e com seus objetivos e a intenção de manter-se ligado a ela para realizar seus próprios desejos.

Na mesma direção, Noronha, Delforno e Pinto (2014) desenvolveram uma pesquisa com 101 professores de diferentes níveis de ensino, sendo $83,2 \%$ do sexo feminino e apenas $16,8 \%$ homens. A amostra foi composta por 18 educadores de Creche, 23 professores de Educação Infantil, 22 de Ensino Fundamental, 20 de Ensino Médio e 18 de Ensino Superior. A coleta foi realizada em sete instituições, das quais cinco eram da rede pública e duas da rede privada, localizadas na região de Campinas-SP. As autoras utilizaram a Escala de Afetos De Zanon que mensuraram os níveis de afetos positivos e negativos presentes nos indivíduos. $O$ intuito do estudo foi comparar afetos positivos e negativos em professores dos diversos níveis de ensino. Os resultados da pesquisa mostraram que os afetos positivos prevalecem na amostra e os profissionais que se dedicavam a creche obtiveram níveis mais baixos de afetos positivos em relação aos demais.

Andrade, Fernandes e Bastos (2013) também realizaram uma investigação sobre as possíveis relações entre comprometimento com a carreira e bem-estar subjetivo em professores universitários. Os autores analisaram que visto como medida geral, o bem-estar subjetivo dos docentes encontrou-se acima da média $(M=3,96, D P=0,47)$, mas que ao ser examinado nas suas dimensões este bem-estar evidenciava alterações importantes. Ficou notória uma predominância de satisfação com a vida $(M=4,08, D P=0,57)$ e dos afetos positivos $(M=3,67, D P=0,57)$ em relação aos afetos negativos $(M=1,85, D P=0,59)$. No estudo também é ressaltado que ainda com os afetos negativos em níveis mais baixos, não significa que estejam totalmente ausentes na amostra. Apontase assim um determinado "equilíbrio" entre os afetos, o que reforça a ideia de bem-estar subjetivo presente na literatura, que se define não devido à inexistência de afetos negativos, mas a um predomínio dos afetos positivos (DIENER, 1995).

Considerando a escola como um cenário em que os alunos, os professores e seus aspectos subjetivos se relacionam e precisam ser compreendidos, o presente trabalho teve como foco central o entendimento dos afetos positivos e afetos negativos no trabalho docente. Apesar de não haver, até o momento, muitas pesquisas sobre o bem-estar subjetivo e os afetos envolvidos no trabalho docente, observa-se um rebaixamento, de modo geral, do sentimento de bem-estar destes profissionais, ressaltando a importância das investigações sobre o assunto. Assim sendo, esta investigação buscou analisar a percepção que os professores apresentam sobre os seus afetos positivos e negativos e compreender a forma como estes fatores impactam no trabalho desenvolvido por estes profissionais

\section{MÉTODO}




\section{PARTICIPANTES}

A amostra foi composta por dez professores do 5 ao 9o ano do Ensino Fundamental de uma escola da rede estadual do interior do Estado de São Paulo. Em relação ao sexo, quatro participantes eram homens e seis mulheres, com idade variando entre 20 a 60 anos $(M=35,6)$. Em relação à área de formação, a amostra foi composta por dois professores de Geografia, três de Matemática, um de História, um de Língua Portuguesa, dois de Ciências Biológicas e um de Educação Física. Dois professores possuem pós-graduação concluída, um em andamento e os demais não possuem ou estão cursando nenhuma especialização.

\section{INSTRUMENTOS}

O instrumento utilizado foi uma entrevista semiestruturada que objetivou investigar como os professores descrevem os afetos positivos e negativos em relação a suas práticas e vivencias ocupacionais. As questões para tal investigação foram referentes a qual é o sentimento que os docentes identificam após um dia de trabalho; qual a frequência experimentada de sentimento de tristeza, nervosismo e preocupação; se o professor se sente feliz quando está em sala de aula; com qual frequência experimenta entusiasmo, alegria, encorajamento e confiança.

\section{PROCEDIMENTO DE COLETA E ANÁLISE DE DADOS}

O estudo foi aprovado pelo Comitê de Ética em Pesquisa, sob registro CAAE no 38386114.0.0000.5515. A coleta ocorreu por meio da realização de entrevistas individuais onde os docentes responderam as perguntas que foram gravadas em áudio. Por se tratar de um estudo qualitativo, optou-se pela Análise de Conteúdo (BARDIN, 2011) para a organização e compreensão dos dados, a partir do agrupamento das respostas dos participantes e a definição de categorias.

\section{RESULTADOS}

No presente estudo, buscou-se investigar o bem-estar no âmbito do trabalho, que é sugerido como um conceito psicológico multidimensional, interligado por elos afetivos positivos com o trabalho, ou uma satisfação e envolvimento com as suas atividades, e também possuir esses afetos com a organização, ou seja, apresentar um comprometimento afetivo com o local onde trabalha (SIQUEIRA; GOMIDE JR, 2004). As respostas dos participantes foram analisadas a partir de duas categorias representativas dos construtos afetos positivos e afetos negativos, elementos do bemestar subjetivo eleito para serem investigados e compreendidos qualitativamente na perspectiva dos professores, que foram ouvidos em relação a suas práticas e seu contexto de trabalho.

\section{DISCUSSÃO}

\section{Categoria 1- Afetos Positivos}

Alguns autores (WATSON; CLARK; TELLEGEN, 1988; MCCULLOUGH; HEUBNER; LAUGHLIN, 2000; DIENER; SUH; OISHI, 1997), colocam que o afeto positivo evidencia o quanto um indivíduo está se sentindo entusiasmado, ativo e alerta, e a frequência de emoções positivas que ele vivencia. As emoções positivas, geralmente, se encontram presentes quando os docentes conseguem encarar e solucionar as dificuldades encontradas, e percebem os momentos de sucesso dentro da sua carreira profissional (ANDRADE; FERNANDES; BASTOS 2013).

Destaca-se entre as verbalizações dos professores fragmentos que indicam experimentação de afetos positivos. Vale ressaltar que, por se tratar de um estudo qualitativo, não houve preocupação com a frequência em que as repostas ocorreram, mas sim com o conteúdo que revelaram.

"Eu me sinto feliz quando eu posso ajudar o aluno a aprender/ eu me realizo nesse processo de aprendizagem... eu me sinto feliz... e quando eu vejo os alunos daqui da escola aprendendo, lendo... 
fazendo perguntas às vezes sobre um texto que nós acabamos de ler... eu penso que é muito bom isso, que é satisfatório..." (Sujeito 4)

"Por incrivel que pareça eu me sinto feliz porque eu gosto de dar aula... eu gosto de estar nesse ambiente... e eu falo isso pra você e é a pura verdade... eu me sinto realizada como professora..." (Sujeito 9)

Nota-se pela fala dos docentes uma expressão positiva sobre suas atividades profissionais, ficando evidenciado que sua vivencia é percebida a partir de afetos positivos e de satisfação com seu trabalho. Já no que diz respeito à resposta dos participantes em relação a vivencia de afetos positivos em sala de aula, de maneira geral, eles afirmam serem muito felizes na profissão, mantendo um discurso firme de que se sentem realizados ensinando, e ficam satisfeitos quando percebem reconhecimento por parte dos alunos e, alegam ainda que mesmo que pudessem não mudariam de profissão.

Noronha et al. (2014), realizaram um estudo com 101 professores de diferentes níveis de ensino sendo 83,2 mulheres e apenas 16,8 do sexo masculino. Foi utilizada a Escala de Afetos de Zanon (EAZ) para mensurar os níveis de afetos positivos e negativos presentes nos professores. Os achados apontaram níveis superiores de afetos positivos e baixos de negativos. Pode-se perceber que tanto na pesquisa das autoras acima quanto no presente estudo ocorreu uma predominância dos afetos positivos quando comparados aos afetos negativos. $\mathrm{O}$ trabalho para os professores parece ter significações positivas, dentre elas a satisfação no trabalho, que é compreendida como sendo um estado emocional positivo, resultado de uma experiencia de trabalho prazerosa (UNGARO, 2007). É possível perceber através das afirmações dos docentes que eles experimentaram na sua pratica afetos positivos, que acarretaram uma satisfação com o trabalho.

Categoria 2 - Afetos Negativos

O afeto negativo, segundo Diener (1995), é um estado transitório que engloba sentimentos desagradáveis, e apresenta características como pessimismo, aborrecimentos, comportamentos ansiosos e angustiantes. Como já foi analisado por Lipp (2002), as dificuldades referentes ao nível elevado de exposição exigido para a realização de atividades de ensino, as inquietações ligadas às modificações na natureza das ações, o possível despreparo para a execução das atividades exigidas pelo cargo, entre outras variáveis pode estar relacionada com as experiências emocionais negativas expressadas pelos docentes. Os pesquisadores Andrade et al. (2013) indicam que essas vivencias de afetos negativos podem acarretar uma diminuição da capacidade do professor para encarar os obstáculos encontrados no seu trabalho. A seguir são reproduzidas as afirmações dos docentes relacionadas ao afeto negativo:

"Tristeza nervosismo e preocupação... não é tão é frequente assim, coisas que todo dia eu tô sentindo essa situação de nervosismo... mas pelo menos uma vez na semana... eu sinto que é um nervosismo..."

É possível perceber na fala do docente aspectos como preocupação, nervosismo e desequilíbrio que são vivenciados na sua pratica profissional, e o quanto esses afetos negativos interferem nas suas atividades e no modo como se sentem no ambiente de trabalho. Os autores Watson et al. (1988) entendem os afetos como registros cerebrais das experiências pessoais, e que o afeto negativo, especificamente, faz referência a um estado de insatisfação temporário com a presença de sentimentos desagradáveis e aversivos, como por exemplo, pessimismo, raiva, desprezo e os que foram citados acima pelos participantes. Abaixo são descritas as falas dos participantes que se relacionam com o fator da falta de confiança e encorajamento dentro do ambiente profissional:

"Poucas vezes... poucas vezes e no ambiente escolar na sala/ na escola de modo geral a gente não é motivado... não há nenhuma preocupação em motivar o professor... e nem fora dela... tipo... delegacia de ensino onde é nossa casa... a gente quase nunca é bem tratado lá... sonegam informações ninguém sabe de nada..." 
Em contrapartida as informações apresentadas nas análises anteriores que mostraram que os professores experimentam afetos positivos, nas verbalizações da categoria afetos negativos, são apresentadas pelos professores falas que apontam vivencias associadas à falta de encorajamento, de confiança e entusiasmo. A respeito disso, cabe a discussão sobre a questão controversa encontrada nas relações entre afetos positivos e afetos negativos que é a independência destes elementos.

Existe um ponto que vem sendo debatido no que se refere às relações entre afeto positivo e afeto negativo, que é a independência entre estes fatores. Costa e McCrae (1980) propuseram com seus estudos realizados com a PANAS que afetos positivos e afetos negativos poderiam ser explicados como extremos contrários de um mesmo construto. Watson et al. (1988) conceituam afeto positivo e afeto negativo como duas esferas diferentes que podem ser apresentadas de modo significativo como dimensões ortogonais nas pesquisas com analise fatorial do afeto, mesmo que os conceitos possam indicar que os fatores sejam opostos. Nas pesquisas atuais sobre a composição fatorial do aspecto afeto no bem-estar subjetivo, os afetos positivos e negativos surgem fortemente como dois extremos dominantes e relativamente independentes.

\section{CONCLUSÃO}

Os resultados encontrados podem contribuir para o entendimento das experiências emocionais do docente dentro do seu ambiente de trabalho e no que elas se relacionam quanto à felicidade, motivação, otimismo, encorajamento destes profissionais.

É importante apontar ainda as limitações apresentadas neste estudo, principalmente no que se refere ao número de participantes, já que se trata de uma amostra pequena quando se refere a uma categoria com grande quantidade de profissionais em exercício. Apesar das restrições presentes no estudo foi possível observar que, de maneira geral, os professores expressaram em suas falas experiências emocionais agradáveis, que lhes remetem o sentimento de felicidade, o que evidencia a presença dos afetos positivos no seu ambiente de trabalho. Mas ainda assim nos chama a atenção o fato destes professores também relatarem com certa frequência sentimentos desagradáveis, o que fazem com que se sintam cansados e insatisfeitos com as condições de trabalho, fatores que podem ser investigados e compreendidos melhor em novas pesquisas com instrumentos e participantes distintos.

\section{REFERÊNCIAS}

ANDRADE, R. S.; FERNANDES, S. R. P.; BASTOS, A. V. B. Bem-estar subjetivo e comprometimento com a carreira: examinando suas relações entre professores de ensino superior. Revista de Psicologia, Fortaleza, v. 4 - n. 2, p. 47-60, jul/dez, 2013. Disponível em: <http://www.periodicos.ufc.br/index.php/psicologiaufc/article/view/805/782>. Acesso em: 15 de Jun. 2016.

BARDIN, L. Análise de conteúdo. São Paulo: Edições 70, 2011.

COSTA, P.; MCCRAE, R. R. Influence of extraversion and neuroticism on subjective well-being: Happy and unhappy people. Journal of Personality and Social Psychology, 38(4), 668-678, 1980. Disponível em: <http://psycnet.apa.org/index.cfm?fa=buy.optionToBuy\&id=1981-10468-001>. Acesso em: 03 de Abr. 2016.

DIENER, E. A value based index for measuring national quality of life. Social Indicators Research, 36, 107-127, 1995. Disponível em: <https://link.springer.com/article/10.1007\%2FBF01079721> Acesso em: 14 de Abr. 2016.

DIENER, E., SUH, E. M., \& OISHI, S. Recent Findings on Subjective Well-Being. University of Illinois, 1997. 
56.unassigned.ntelos.net/images/stories/library/Stennett Psychology Articles/Recent\%20Findings\% 20on\%20Subjective\%20Well-Being.pdf >. Acesso em: 14 de Abr. 2016.

GIACOMONI, C. H. Bem-estar subjetivo: em busca da qualidade de vida. Temas psicol., Ribeirão Preto, v. 12, n. 1, p. 43-50, jun. $2004 . \quad$ Disponível em $<$ http://pepsic.bvsalud.org/scielo.php?script=sci_arttext\&pid=\$1413389X2004000100005\&lng=pt\&nr $\mathrm{m}=$ iso $>$. Acessos em 04 Mar. 2016.

Lipp, M. N. O Stress do Professor. Campinas: Papirus, 2002.

MCCULLOUGH, G.; HUEBNER, E.; LAUGHLIN, J. Life events, self-concept, and adolescents' positive subjective well-being. Psychology in the Schools, 37 (3), 281-290, 2000. Disponível em: $<$ http://onlinelibrary.wiley.com/doi/10.1002/(SICI)1520-

6807(200005)37:3\%3C281::AIDPITS8\%3E3.0.CO;22/epdf?r3 referer=wol\&tracking action=preview c lick\&show checkout=1\&purchase referrer=www.google.com.br\&purchase site license=LICENSE DE NIED>. Acesso em: 23 de Jun. 2016.

NORONHA, A. P. P.; DELFORNO, M. P.; PINTO, L. P. Afetos positivos e negativos em professores de diferentes níveis de ensino. Revista Quadrimestral da Associação Brasileira de Psicologia Escolar e Educacional, $S P . \quad$ v. 18, n2, Maio/Agosto, $2014 . \quad$ Disponível em: <http://www.scielo.br/pdf/pee/v18n2/1413-8557-pee-18-02-0211.pdf>. Acesso em: 14 de Mar. 2016.

SELIGMAN, M.E.P. Felicidade Autêntica: usando a nova psicologia positiva para a realização permanente. Rio de Janeiro: Objetiva, 2004.

SIQUEIRA, M. M. M.; GOMIDE JR., S. Vínculos do indivíduo com o trabalho e com a organização. Em J. C. Zanelli, J. E. Borges-Andrade \& A. V. B. Bastos (Orgs), Psicologia, organizações e trabalho no Brasil (pp. 300-328). Porto Alegre: Artmed, 2004.

UNGARO, S. F. V. (2007). A satisfação no trabalho e a relação com o afecto positivo, afecto negativo, sistema de recompensas e plano de benefícios: Estudo realizado a professores de treze ginásios pertencentes ao distrito do Porto e arredores. Tese de Mestrado em Ciências do Desporto. 246 p. Universidade do Porto, Portugal, $2007 . \quad$ Disponível em: $<$ https://sigarra.up.pt/fdup/pt/pub geral.pub view?pi pub base id=22610 $>$. Acesso em: $14 \mathrm{de} \mathrm{Mar}$. 2016.

WATSON, D.; CLARK, L. A.; TELLEGEN, A. Development and validation of brief measures of positive and negative affect: The PANAS scales. Journal of Personality and Social Psychology, 54(6), 10631070, $1988 . \quad$ Disponível em: $<$ https://pdfs.semanticscholar.org/7124/10f2b20c831678f71db35ec01ba1b38bc842.pdf>. Acesso em: 17 de Mar. 2016. 